\title{
Recycled household ceramic waste in eco-efficient cement: A case study
}

Yining Ding ${ }^{a}$, Huiwen Dong ${ }^{a}$, Mingli Cao ${ }^{a}$, F. Pacheco-Torgal ${ }^{b}$, Cecilia Azevedo ${ }^{c}$

${ }^{a}$ State Key Laboratory of Coastal and Offshore Engineering, Dalian University of

Technology, Dalian, China, ${ }^{b} \mathrm{C}$-TAC Research Centre, University of Minho, Guimarães,

Portugal, 'University of Minho, Centre of Mathematics, Minho, Portugal

\subsection{Introduction}

The current world cement production amounts near 3 billion tons/per year. Portland cement demand decreases in industrial nations and increases dramatically in developing countries. Global demand will have increased by almost $200 \%$ by 2050 from 2010 levels. The total cement output in China was about 2.48 billion tons in 2014, and this trend will continue. It is known (Ding et al., 2010) that around 1 ton of carbon dioxide is emitted for each ton of cement production (Fig. 17.1A). It is very serious for climate change caused by $\mathrm{CO}_{2}$ emissions worldwide. Consequently, it is important to take effective measures to reduce the carbon dioxide pollution caused by the cement industry.

Meanwhile, China is the world's leading manufacturer of ceramics; as a result, more than 100 million tons of ceramic wastes are produced each year. The ceramic waste is a serious problem, as there is between $10 \%$ and $20 \%$ waste from the processing procedures. Only in Guangdong province near Hong Kong, the ceramic waste and waste sludge are about 10 million tons each year. The disposal of this waste not only occupies large areas of land but can also severely pollute the environment (Fig. 17.1B and C). Hence, the correct treatment of ceramic waste is necessary to preserve the environmental degradation. The reuse of such waste can not only protect the environment but also offers a great advantage in partial replacement of cement in concrete for example.

There have been several previous studies that have investigated the use of powdered igneous, metamorphic rocks or zeolites as pozzolanic materials (Ding et al., 2010; Kitsopoulos and Dunham, 1996; Pedersen, 2004; Mertens et al., 2009) and the use of ceramic waste as aggregate in concrete (De Brito et al., 2004; Silvestre et al., 2013). The replacement of Portland cement by powered igneous increased the compressive strength (Kitsopoulos and Dunham, 1996). The surface area only influences the shortterm reactivity, and the long-term reactivity is mainly related to the $\mathrm{Si} / \mathrm{Al}$ ratio of the zeolites (Mertens et al., 2009). The investigation on the ceramic roof tile wastes and clay bricks (CB) as pozzolanic admixture has also been conducted, and the calcined clay wastes from Britain, Denmark, Lithuania, and Poland are suitable for partial replacement of cement without a detrimental effect on the strength (Lavat et al., 2009;

Advances in Construction and Demolition Waste Recycling. https://doi.org/10.1016/B978-0-12-819055-5.00017-6 (C) 2020 Elsevier Ltd. All rights reserved. 



Fig. 17.1 Pollution of the cement industry and ceramic waste on the environment: (A) cement industry in China; (B) household ceramic waste; and (C) clay bricks waste.

Wild et al., 1997). Matias G. reviewed the significant research related to heat-treated clays and ceramics (roof tiles, bricks, and pottery) incorporated in old mortars (Matias et al., 2014a, b).

The objectives of the research about ceramic waste include a number of issues such as the microstructure, chemical and physical behavior, mechanical properties and manufacturing, the durability and fire resistance, and the freeze-thaw property and cracking resistance. However, it is not intended in this study to present a complete knowledge of every aspect of the ceramic waste. Here, we focus only on the investigation of the ceramic waste from South China. The household ceramic (HC) is a large part of all the ceramic production types and the exports of $\mathrm{HC}$ accounted for about $65 \%$ of total ceramic output. It means that the ceramic products go to abroad and the pollution remains in the home country. But, the study on reusing of the recycled HC and $\mathrm{CB}$ waste was still very limited, and no literature regarding the pozzolanic activity of $\mathrm{HC}$ waste materials was found. The aim of this study is to evaluate the possibility of partial substitution of Portland cement with $\mathrm{HC}$ and $\mathrm{CB}$ waste powder to produce environmental-friendly cement or concrete.

In order to analyze the possible reuse of crushed ceramic waste powder as a cementitious material for replacing of Portland cement, the pozzolanic reactivity of the $\mathrm{HC}$ waste powder and $\mathrm{CB}$ waste powder have been investigated in this work. The comparison of the crystallinity degree between the $\mathrm{CB}$ waste and $\mathrm{HC}$ waste has been carried out. In addition, mortars containing fly ash (FA) as the referenced pozzolanic material were also studied to compare the properties of pastes that contain $\mathrm{HC}$ or $\mathrm{CB}$ powder.

The powdered $\mathrm{HC}, \mathrm{CB}$ waste, and FA (as the referenced pozzolanic material) were used to replace cement in the ratio of 5\%,15\%, and $25 \%$. The chemical composition, the flowability, and crystal structures, especially the pozzolanic activity of the $\mathrm{HC}$ and CB waste powder are investigated. The evaluation of the pozzolanic activity using Frattini and strength activity index (SAI) testing method is meaningful for the possible replacement of cement. It is desirable that $\mathrm{HC}$ and $\mathrm{CB}$ wastes could be used in partial substitution of Portland cement both by their beneficial effect on the properties of cement as well as by the economic and ecologic advantage, and the market for the new pozzolanic material may be enormous: as mentioned, more than 2 billion tons of cement is produced annually in China, so 5\% replacement of cement would require some 10 million tons of pozzolanic materials and reduce the similar amount of $\mathrm{CO}_{2}$ emission. 


\subsection{Experiment}

\subsubsection{Testing materials}

The HC waste and CB waste were obtained from Province Kuangdong in South China. The maximum heating temperature for household/tableware ceramics ranged between $1100^{\circ} \mathrm{C}$ and $1300^{\circ} \mathrm{C}$. The maximum heating temperature for $\mathrm{CB}$ was at least $950^{\circ} \mathrm{C}$ and ranged between $950^{\circ} \mathrm{C}$ and $1100^{\circ} \mathrm{C}$. The time period at maximum temperature was unavailable by the ceramic companies. In summer, the exterior weather condition in the province is very humid and sultry. The relative humidity ranged between $80 \%$ and $95 \%$. The FA was used as referenced pozzolanic material. The mix design is listed in Table 17.1. The Portland Cement (PO) CEM I 42.5 with a specific surface area of $330 \mathrm{~m}^{2} / \mathrm{kg}$, FA with the specific surface area of $516 \mathrm{~m}^{2} / \mathrm{kg}$, the HC waste powder with a specific surface area of $530 \mathrm{~m}^{2} / \mathrm{kg}$ and $\mathrm{CB}$ waste powder with a specific surface area of $690 \mathrm{~m}^{2} / \mathrm{kg}$ were used, respectively (see Table 17.2). The ceramic wastes replace 5\%, 15\%, and 25\% of cement. The sand used conformed to ISO 679: 2009 (ISO 679, 2009). The control sample of $100 \%$ Cem-I (PO) without waste addition was also used for comparison of SAI values. The water/binder ratio was 0.5 . The specific surface area of CB powder is higher than that of HC powder. The study of Mertens G. et al. showed that the external surface area only influences the short-term reactivity, whereas the cation content has an effect on both the long- and short-term reactivity (Mertens et al., 2009).

\subsubsection{Grain size analysis}

Ceramic wastes were ground by a ball mill for 24 h. Based on ISO 13320-2009, the equipment GSL-101B for Laser Granulometry for Particle Size Analysis (with Measuring range between 0.15 and $400 \mu \mathrm{m}$ ) has been used. The ethanol was applied as a wetting agent for the wet dispersion of particles. The particle size distribution of cement, FA, HC, and CB waste powder is illustrated in Fig. 17.2.

Table 17.1 Mix-design of mortars.

\begin{tabular}{|l|l|l|l|l|l|}
\hline & $\begin{array}{l}\text { Cement } \\
(\mathbf{g})\end{array}$ & HC/CB/FA $(\mathbf{g})$ & $\begin{array}{l}\text { Water } \\
(\mathbf{g})\end{array}$ & ISO sand $(\mathrm{g})$ & W/B \\
\hline PO (CEM-I) & 450 & 0 & 225 & 1350 & 0.5 \\
HC5/CB5/FA5 & 427.5 & 22.5 & 225 & 1350 & 0.5 \\
HC15/CB15/FA15 & 382.5 & 67.5 & 225 & 1350 & 0.5 \\
HC25/CB25/FA25 & 337.5 & 112.5 & 225 & 1350 & 0.5 \\
\hline
\end{tabular}

Table 17.2 Comparison of the specific surface area.

\begin{tabular}{|l|l|l|l|l|}
\hline & CEM & FA & HC & CB \\
\hline Specific surface area $\left(\mathrm{m}^{2} / \mathrm{kg}\right)$ & 330 & 516 & 530 & 690 \\
\hline
\end{tabular}




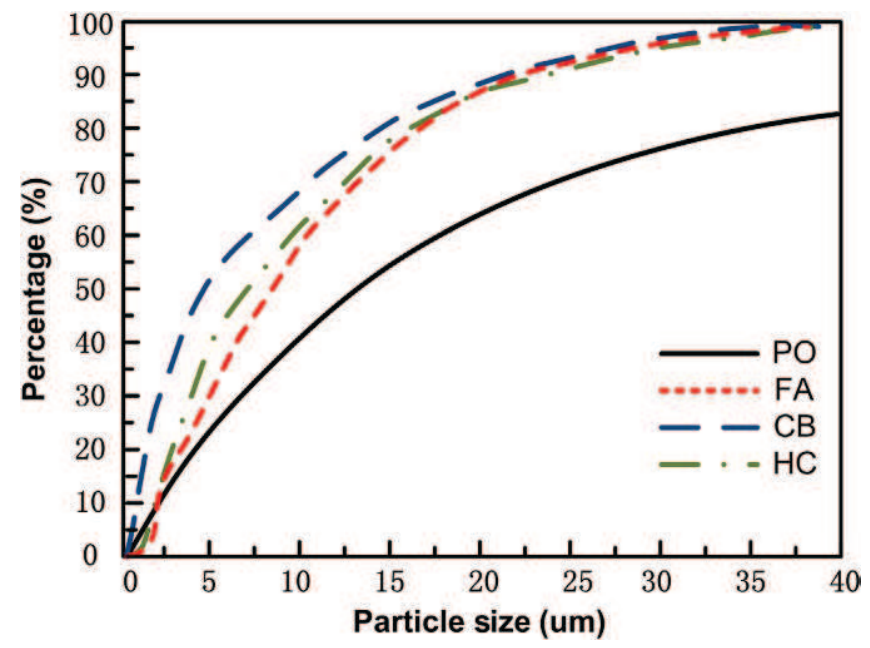

Fig. 17.2 Particle size distribution of different powders.

From Fig. 17.2, it can be seen that for any particular size the percentage of ceramic waste powder ( $\mathrm{HC}$ and $\mathrm{CB}$ ) and FA was greater than that of cement. The most part (almost 100\%) of the ceramic waste powder and FA was smaller than $40 \mu \mathrm{m}$. The FA, $\mathrm{HC}$, and $\mathrm{CB}$ powders were ground to very fine grain size: $90 \%$ of powders were under $25 \mu \mathrm{m}$ and $30 \%$ powders were under $5 \mu \mathrm{m}$. The particle size distribution may show a clear influence on the total specific pore volume of the cement or concrete matrix. The finer the powders particle size results in the denser paste and the smaller pore volume in the matrix.

\subsubsection{Chemical analysis}

The alkali environment of mortar or concrete matrix is an important factor for durability. The aim of the present investigation is to use the recycled ceramic waste powder as a part of the mortar or concrete. Hence, the matrix should have a similar alkali ambient to normal cement. The lower boundary of $\mathrm{pH}$ value of ceramic waste powder was limited, in order to avoid the reduction of the general alkali value of the concrete matrix. The evaluation of the $\mathrm{pH}$-value of cement, ceramic waste powder, and FA solution was carried out (see Table 17.3). It can be seen that $\mathrm{pH}$-values of $\mathrm{HC}$ and $\mathrm{CB}$ waste powder are higher than 9, and $\mathrm{HC}$ powder could be more suitable for use in cement or concrete matrix than that of $\mathrm{CB}$ powder.

The equipment XRF-1800 (X-ray fluorescence with a scanning speed of $20 \% \mathrm{~min}$ ) for analysis of the chemical compositions has been used. The chemical compositions

Table 17.3 pH-values of different materials.

\begin{tabular}{|l|l|l|l|l|}
\hline & PO & CB & HC & FA \\
\hline $\mathrm{pH}$ & 12.46 & 9.24 & 10.41 & 11.94 \\
\hline
\end{tabular}


Table 17.4 Comparison of the chemical composition of PO (cement), FA, and ceramic waste powder.

\begin{tabular}{|l|l|l|l|l|}
\hline & PO & CB & HC & FA \\
\hline $\mathrm{SiO}_{2}$ & 28.43 & 60.6 & 71.03 & 49.1 \\
$\mathrm{Al}_{2} \mathrm{O}_{3}$ & 6.95 & 20.35 & 18.22 & 26.2 \\
$\mathrm{Fe}_{2} \mathrm{O}_{3}$ & 2.44 & 11.01 & 2.59 & 10.0 \\
$\mathrm{~K}_{2} \mathrm{O}$ & 1.06 & 4.77 & 4.66 & 1.58 \\
$\mathrm{TiO}_{2}$ & 0.36 & 1.37 & & 1.88 \\
$\mathrm{MgO}$ & 4.3 & 1.02 & 0.33 & 1.23 \\
$\mathrm{Na} 2 \mathrm{O}$ & 0.16 & 0.25 & 1.03 & 0.641 \\
$\mathrm{CaO}$ & 52.21 & 0.17 & 0.57 & 8.52 \\
$\mathrm{MnO}$ & 0.08 & & 0.13 & \\
$\mathrm{PbO}$ & & & 0.58 & 0.1 \\
$\mathrm{ZrO}$ & & 0.28 & 0.036 \\
$\mathrm{ZnO}$ & 0.065 & & 0.2 & \\
$\mathrm{CdO}$ & 0.043 & & 0.18 & 0.533 \\
$\mathrm{Rb}$ & & 0.11 & \\
$\mathrm{SO}$ & & & & \\
\hline
\end{tabular}

of CEM, FA, HC and CB powder were analyzed and the results are presented in Table 17.4. The main chemical components of ceramic waste powder are similar to those of FA and consist mainly of $\mathrm{SiO}_{2}$ and $\mathrm{Al}_{2} \mathrm{O}_{3}$. Combined with Fig. 17.3, it can be seen that $\mathrm{SiO}_{2}$ of $\mathrm{HC}$ shows a low degree of crystallinity, it is similar to that of FA. $\mathrm{SiO}_{2}$ with a low degree of crystallinity may be expected to contribute to the pozzolanic activity of ceramic waste powder. If the content of $\mathrm{K}_{2} \mathrm{O}$ is high, the cement will set rapidly and the water requirement may increase. At the same time, $\mathrm{K}_{2} \mathrm{O}$ in the cement may generate potassium gypsum $\left(\mathrm{K}_{2} \mathrm{SO}_{3} \mathrm{CaSO}_{4} 2 \mathrm{H}_{2} \mathrm{O}\right)$ and reduce the strength. The higher the alkali increase, the lower the compressive strength of cement pastes (Smaoui et al., 2005; Selman and Ali, 2012).

\subsubsection{Workability of different mixtures}

Based on China National Guideline GB/T 2419-2005 (Test method for fluidity of cement morta) (GB/T 2419-2005, 2005), the experiment for fresh mortar has been carried out. Table 17.5 illustrates the flowability of mortars with different ratios of ceramic waste powder and FA substitutions. It can be seen that the ceramic waste powder does not exert negative influence on the workability of the mortar if the substitution ratio is lower than $25 \%$.

\subsubsection{XRD analysis}

The equipment XRD-6000 (X-ray diffraction with scan range between $5^{\circ}$ and $80^{\circ}$ ) for analysis of the crystal structures and amorphous behavior of the materials has been used. The XRD testing of cement, FA, HC, and CB waste powder is carried out. The crystallinity of the materials is a structural factor and plays an important role in the 

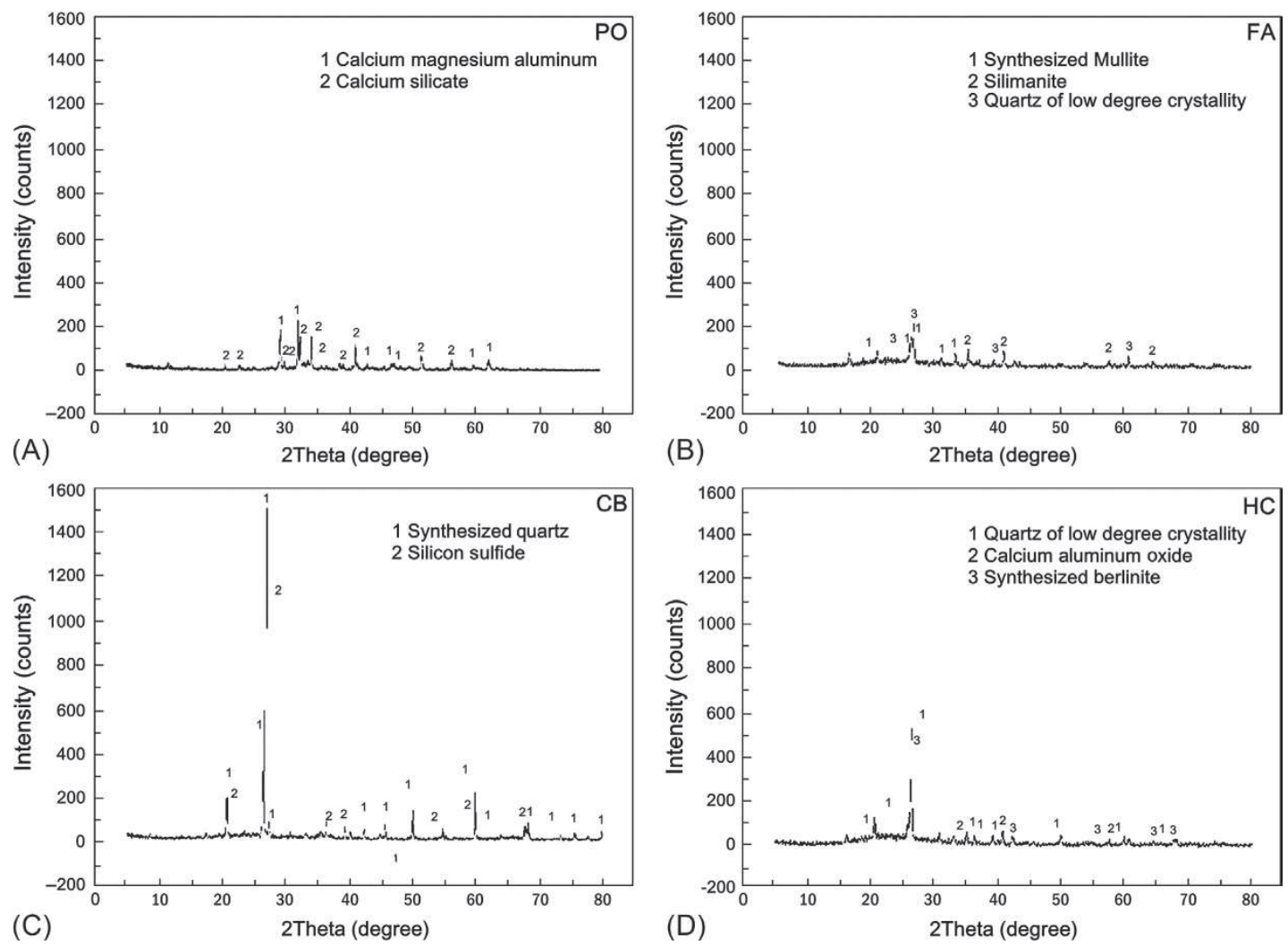

Fig. 17.3 XRD pattern of different powders: (A) PO; (B) FA; (C) CB powder; and (D) HC powder. 
Table 17.5 Flowability of different fresh mortars.

\begin{tabular}{|l|l|l|l|l|l|l|l|l|l|l|}
\hline Mixture & PO & HC5 & HC15 & HC25 & CB5 & CB15 & CB25 & FA5 & FA15 & FA25 \\
\hline $\begin{array}{l}\text { Flowability } \\
(\mathrm{mm})\end{array}$ & 176 & 175 & 189 & 188 & 170 & 166 & 162 & 177 & 184 & 189 \\
\hline
\end{tabular}

pozzolanic activity, causing different rates of reaction of the active phase (Tironi et al., 2013). The XRD analysis is one of the preconditions for further investigation of the pozzolanic activity. The results are presented in Fig. 17.3.

From Fig. 17.3A, it can be seen that the PO (sample of $100 \%$ cement) shows very slight crystalline behavior. The peak intensity is about 250 counts only. The calcium magnesium aluminum is the main crystalline forms detected while calcium silicate is the minor compound. Fig. 17.3B indicates that quartz of low degree crystallinity is the main compound with synthesized mullite and sillimanite as minor compounds in the FA. For the waste powder of CB, Fig. 17.3C indicates that synthesized quartz of high degree of crystallinity is the main component together with silicon sulfide. The peak intensity of $\mathrm{CB}$ achieves about 1600 counts. Fig. 17.3D reflects that quartz of low degree crystal is the main compound detected in the test accompanied by calcium aluminum oxide and synthesized berlinite as the minor compounds in the HC waste powder. The peak intensity of HC achieves about 500 counts, it is much lower than that of $\mathrm{CB}$ powder, and the average intensity of $\mathrm{HC}$ powder shows low crystalline degree. Compared to PO (cement), FA, and CB, it can be seen that $\mathrm{HC}$ waste powder shows very few high peak intensities due to the slightly crystalline structure (Fig. 17.3D). The average crystalline degree of HC powder was similar to that of the reference powder of FA, and the HC waste powder illustrates the clear amorphous structure, which indicates that the crushed $\mathrm{HC}$ powder could be used as both pozzolanic material and as fine filler.

\subsubsection{Pozzolanic activity}

For evaluation of the pozzolanic activity of the materials, it is important to consider the experimental method. Previous studies indicated that the Frattini test (as direct method) and the SAI test (as indirect method) are found to be the most accurate and reliable methods to assess the pozzolanic reaction of calcined clays in blended types of cement (Shi, 2001; He et al., 1995; Donatello et al., 2010; Tironi et al., 2013; Malquori, 2013). The evaluation of pozzolanic materials for purpose of the addition into Portland cement should be based on two factors (Malquori, 2013): (1) the strength of mortars and concretes made with a Portland pozzolan mixture, and (2) the reduction of free calcium hydroxide in the hardened pozzolanic cement. In addition, the Chapelle test may be also a selective method for testing of pozzolanic reactivity; however, the previous investigation showed that there is a low correlation between the results of Fratinni test and Chapelle test (Pontes et al., 2013) in some cases. Therefore, in this article, both the Frattini test and the SAI test are used to evaluate the pozzolanic activity of ceramic waste blended cement. 


\subsubsection{Strength activity index (SAI) of different mortars}

The significant behavior for pozzolanic activity can be evaluated by the compression strength. The control sample of $100 \%$ cement without any waste addition was introduced for strength comparison. In order to evaluate the compressive strength of blended cement, the concept of SAI is used. SAI is defined as the ratio of the compressive strength of cement with additional waste powder to the compressive strength of cement without any addition (SAPRC (Standardisation Administration of the People's Republic of China), 2005; SBQTS (State Bureau of Quality and Technical Supervision), 1999; British Standard (BS) 3892, 1997; American Society for Testing and Materials (ASTM) C618, 2005). The ceramic waste powder may show pozzolanic activity, if SAI is greater than 0.65 (SAPRC (Standardisation Administration of the People's Republic of China), 2005), 0.8 (British Standard (BS) 3892, 1997), or 0.75 (American Society for Testing and Materials (ASTM) C618, 2005) with cement replacement of 10\%, 20\%, and 30\% after 28 days based on different guidelines (SAPRC (Standardisation Administration of the People's Republic of China), 2005; SBQTS (State Bureau of Quality and Technical Supervision), 1999; British Standard (BS) 3892, 1997; American Society for Testing and Materials (ASTM) C618, 2005).

Prismatic specimens of $40 \mathrm{~mm} \times 40 \mathrm{~mm} \times 160 \mathrm{~mm}$ were cast and wet cured at $20^{\circ} \mathrm{C}$ (Malquori, 2013; SAPRC (Standardisation Administration of the People's Republic of China), 2005). The results of compressive strengths and SAI values (or the control sample strength: Compression strength of $\mathrm{PO} / \mathrm{Comparison}$ strength of $\mathrm{HC}, \mathrm{CB}$, and FA) of various mortars at different ages (1d, 7d, 28d) are listed in Tables 17.6 and 17.7.

In comparison with the PO samples without ceramic waste powder, it can be seen that:

The compressive strength of the samples with $15 \%$ of HC showed the highest value of all the ceramic powders and increased $11 \%$ compared to the value of the PO at 1 day.

At 1 day, the compressive strengths of the samples with $\mathrm{CB}$ powders were lower than those with $\mathrm{HC}$ powder and decreased with the increasing of the $\mathrm{CB}$ powder content.

Table 17.6 Comparison of compressive strengths of various mortars at different ages.

\begin{tabular}{|l|l|l|l|l|l|l|l|l|l|l|}
\hline $\mathbf{N} / \mathbf{m m}^{2}$ & PO & HC5 & HC15 & HC25 & CB5 & CB15 & CB25 & FA5 & FA15 & FA25 \\
\hline 1d & 9.0 & 6.3 & 9.9 & 9.6 & 6.1 & 5.6 & 4.9 & 12.1 & 9.7 & 8.5 \\
7d & 37.8 & 36.1 & 32.8 & 30.7 & 37.6 & 33.5 & 28.4 & 37.0 & 35.1 & 34.1 \\
28d & 45.6 & 46.5 & 49.6 & 44.1 & 46 & 43 & 40 & 49.6 & 45.6 & 42.4 \\
\hline
\end{tabular}

Table 17.7 Comparison of SAI values of various mortars at different ages.

\begin{tabular}{|l|l|l|l|l|l|l|l|l|l|l|}
\hline & PO & HC5 & HC15 & HC25 & CB5 & CB15 & CB25 & FA5 & FA15 & FA25 \\
\hline 1d & 1 & 0.71 & 1.11 & 1.08 & 0.68 & 0.63 & 0.55 & 1.35 & 1.09 & 0.95 \\
7d & 1 & 0.95 & 0.87 & 0.81 & 0.99 & 0.89 & 0.75 & 0.98 & 0.93 & 0.90 \\
28d & 1 & 1.02 & 1.09 & 0.97 & 1.01 & 0.94 & 0.88 & 1.09 & 1 & 0.93 \\
\hline
\end{tabular}


The compressive strengths of all HC, CB, and FA samples decreased with the increasing of powder content at 7 days, and all the SAI values of $\mathrm{HC}, \mathrm{CB}$, and FA were higher than 0.8 except $\mathrm{CB} 25$. It means that the $\mathrm{HC}$ and $\mathrm{CB}$ powder could show pozzolanic activity. However, both the pozzolanic activity and fine filler effect of waste powder may affect the compressive strength, and it is difficult to distinguish the two effects.

At 28 days, the compressive strength of HC5 and CB5 samples increased slightly, whereas $\mathrm{HC} 25$, CB15, and CB25 decreased. This may imply that $15 \%$ of $\mathrm{HC}$ powder could be a possible upper bound for an effective substitution.

At 28 days, all the SAI values of $\mathrm{HC}$, $\mathrm{HCl}$, and $\mathrm{HC} 25$ samples without further heating treatment are higher than 0.9 and the corresponding values of FA, indicating that $\mathrm{HC}$ waste powders may show well pozzolanic activity, which could be very cost-efficient for industrial use. The SAI values of CB5 and CB15 samples without further heating treatment are also higher than 0.9, but lower than the corresponding values of FA.

\subsubsection{Frattini test}

The previous study of Pontes J. suggested that Frattini results should only be applied up to 8 days (Pontes et al., 2013). Our Frattini test was conducted after 8 days curing at $40^{\circ} \mathrm{C}$ according to the EN 196-5, 2011 (British Standard Euronorm (BS EN) 196, 2011). The results are presented as a hyperbolic curve related to the calcium ion [CaO] concentration vs hydroxyl ion $\left[\mathrm{OH}^{-}\right]$concentration (Fig. 17.4).

The interaction relationship of $[\mathrm{CaO}]$ and $\left[\mathrm{OH}^{-}\right]$concentrations expresses the lime solubility curve and divides the $[\mathrm{CaO}]-\left[\mathrm{OH}^{-}\right]$domain into an upper pozzolanic inactive region and a lower pozzolanic active region. Between 35 and $90 \mathrm{mmol} / \mathrm{L}$ $\left[\mathrm{OH}^{-}\right]$, the theoretical maximum $[\mathrm{CaO}]$ concentration can be calculated according to Eq. (17.1) (Donatello et al., 2010):

$$
\max [\mathrm{CaO}]=350 /\left(\left[\mathrm{OH}^{-}\right]-15\right)
$$



Fig. 17.4 Frattini test results for blended cement containing FA, HC, and CB powder. 
Table 17.8 Frattini test results for nine different materials quantified using Eq. (17.1).

\begin{tabular}{|l|l|l|l|l|}
\hline Number & {$\left[\mathbf{O H}^{-}\right]$} & {$[\mathbf{C a O}]$} & Theoretical max $[\mathbf{C a O}]$ & {$[\mathbf{C a O}]$ reduction } \\
\hline & $\mathrm{mmol} / \mathrm{L}$ & $\mathrm{mmol} / \mathrm{L}$ & $\mathrm{mmol} / \mathrm{L}$ & $\%$ \\
$\mathrm{HC5}$ & 53.93 & 4.47 & 8.99 & 50.3 \\
$\mathrm{HC} 15$ & 53.07 & 4.39 & 9.19 & 52.3 \\
$\mathrm{HC} 25$ & 47.29 & 5.83 & 10.84 & 46.2 \\
$\mathrm{CB} 5$ & 50.29 & 6.28 & 9.92 & 36.7 \\
$\mathrm{CB} 15$ & 49.64 & 6.17 & 10.1 & 38.9 \\
$\mathrm{CB} 25$ & 49.2 & 5.92 & 10.23 & 42.1 \\
FA5 & 49.86 & 4.82 & 10.04 & 52 \\
FA15 & 43.66 & 5.94 & 12.21 & 51.34 \\
FA25 & 41.52 & 7.7 & 13.2 & 42 \\
\hline
\end{tabular}

The sample calcium concentration $[\mathrm{CaO}]$ measured can be compared to the theoretical maximum $[\mathrm{CaO}]$ and the result quantified as the difference between the two values. Finally, this is expressed as a percentage of the theoretical maximum removed in Table 17.8.

From Table 17.8, it can be observed that:

The $\left[\mathrm{OH}^{-}\right]$concentration of the $\mathrm{HC}$ waste is in the range between 47 and $54 \mathrm{mmol} / \mathrm{L}$, and the $\left[\mathrm{OH}^{-}\right]$concentration of the $\mathrm{CB}$ waste is lower than the corresponding value of $\mathrm{HC}$ waste powder. Compared to $\mathrm{HC} 5$, the $\left[\mathrm{OH}^{-}\right]$and $[\mathrm{CaO}]$ concentrations of $\mathrm{HC} 15$ changed very slightly, only $2 \%$ and $1 \%$, respectively. However, compared to $\mathrm{HC} 15$, the $\left[\mathrm{OH}^{-}\right]$and $[\mathrm{CaO}]$ concentrations of $\mathrm{HC} 25$ changed about $11 \%$ and $32.8 \%$, respectively.

The pozzolanic activity of $\mathrm{HC} 5, \mathrm{HC} 15, \mathrm{FA} 5$, and FA15 is relatively high with more than $50 \% \mathrm{CaO}$ consumed; whereas $\mathrm{CB} 5, \mathrm{CB} 15, \mathrm{CB} 25, \mathrm{HC} 25$, and $\mathrm{FA} 25$ may show relative low pozzolanic activity, with $37 \%$ and $46 \% \mathrm{CaO}$ consumed.

Similar to SAI test, the results above imply that $15 \%$ of $\mathrm{HC}$ waste powder could be a possible threshold for an effective substitution.

The values of $[\mathrm{CaO}]$ reduction of $\mathrm{CB} 5 / \mathrm{CB} 15 / \mathrm{CB} 25$ are clear less than the values of HC5/ $\mathrm{HC} 15 / \mathrm{HC} 25$, so the $\mathrm{CB}$ waste powder may show lower pozzolanic activity than that of $\mathrm{HC}$ waste powder.

As mentioned, for materials like $\mathrm{HC}, \mathrm{CB}$, and $\mathrm{FA}$, the $\left[\mathrm{OH}^{-}\right]$and $[\mathrm{CaO}]$ concentrations are interrelated, and the correlation is represented by a $\left[\mathrm{OH}^{-}\right]-[\mathrm{CaO}]$ curve (solubility line) in Fig. 17.4. It can be seen that the results of pastes containing HC5, HC15, HC25, CB5, CB15, CB25, FA5, FA15, and FA25 are lying below the solubility line. It indicates that the $\left[\mathrm{Ca}^{2+}\right]$ released by cement hydration to the solution was consumed due to the progress of the pozzolanic reaction and represents some pozzolanic active properties.

\subsubsection{Relationship between the results of SAI test and Frattini test}

The previous investigations (Lavat et al., 2009; Wild et al., 1997; ISO 679, 2009; Shi, 2001; He et al., 1995; Donatello et al., 2010; Tironi et al., 2013) showed that the Frattini test and the SAI test may be suitable for analyzing of the pozzolanic activity of various materials in blended cement. The Frattini test results provide an insight into 
the likely $\mathrm{Ca}(\mathrm{OH})_{2}$ concentration in the pore solution of SAI samples. For both methods, $\mathrm{HC} 15$ showed the highest activity, and the removal of $\mathrm{Ca}(\mathrm{OH})_{2}$ from solution in the Frattini test indicates that in the SAI test sufficient reaction between $\mathrm{HC} 15$ and pore solution $\mathrm{Ca}(\mathrm{OH})_{2}$ occurs to form strength providing $\mathrm{C}-\mathrm{S}-\mathrm{H}$ gel-type phases after 28 days. However, for cement with CB addition, the two results between Frattini test and the SAI test are not very consistent. Based on the SAI values in Table 17.6, CB indicates lower activity than those of FA and $\mathrm{HC}$ after 7 days, especially for CB25.

As mentioned in the introduction, FA as the referenced pozzolanic material was introduced to compare the properties with pastes that contain HC or CB powder. Fig. 17.5 illustrates the relationship of pozzolanic activity results of FA between the Frattini test and SAI test at 28 days. The unit of $\mathrm{X}$ is dimensionless and equal to the control sample strength (comparison strength of FA, HC, and CB samples/Compression strength of the cement sample).

For samples with FA powder, there is a positive linear correlation between results from Frattini (CaO removed in \%) test and SAI test (Donatello et al., 2010), in other words, the compression strength of samples with different ratios of FA powder increases linearly with the increasing of the consumed $\mathrm{CaO}$. The relationship between Frattini (denoted by Y) and SAI (denoted by X) can be expressed in the following equation:

$$
Y=a X+b
$$

where a denotes the slope of fitting line and $\mathrm{b}$ denotes the intercept. The slope is an important factor and illustrates the amount of $\mathrm{CaO}$ removed\% divided by per unit of SAI; for substitution ratios with FA powder between $5 \%, 15 \%$, and $25 \%, a=59.93$. The Frattini results and SAI results are strong correlated $(R=0.86)$.



Fig. 17.5 Correlation between Frattini test and SAI results of FA. 




Fig. 17.6 Correlation between Frattini test and SAI results of HC.

Fig. 17.6 illustrates the relationship between Frattini test and SAI results of samples with HC waste powder. Similar to FA powder, for samples with HC waste, there is also a clear positive linear correlation between results of $\mathrm{CaO}$ removed in $\%$ and SAI.

From Fig. 17.6, it can be seen that for substitution ratios with HC powder between $5 \%, 15 \%$, and $25 \%$, the slope $a=49.4$. The Frattini and SAI results are also strongly correlated $(R=0.958)$. The slope for HC powder is lower than that for FA powder $(49.4<59.93)$. It may imply that the amount of $\mathrm{CaO}$ removed\% of $\mathrm{HC}$ samples is less than that of FA samples for per unit of SAI, and the pozzolanic activity of FA is higher than that of HC.

Fig. 17.7 illustrates the relationship between Frattini test and SAI results for CB powder. Opposed to the discussions in Figs. 17.5 and 17.6, there is a negative linear correlation between the two tests with the replacement of $5 \%, 15 \%$, and $25 \%$ of CB waste powder, the slope $a=-41.26$, and opposed to Figs. 17.5 and 17.6, the $\mathrm{CaO}$ consumed declines with the increasing of SAI. It may reflect the low magnitude of the pozzolanic activity of $\mathrm{CB}$ powder; the reason could be traced back to the following points:

- Based on the XRD analysis in Section 17.2.5, CB waster powder shows quartz of high degree crystallinity accompanied by silicon sulfide.

- The SAI values of blended cement can be affected by two factors: the pozzolanic activity and the fine filler effect of CB powder; however, the effect between the two factors of waste powder on the compressive strength cannot be separated quantitatively.

- Qualitatively, the fine filler effect of CB powder may show higher influence on the SAI values than that of pozzolanic activity; and a large part of fine-milled CB powder may be still unreacted and plays a role as fine filler due to the large specific surface area. 


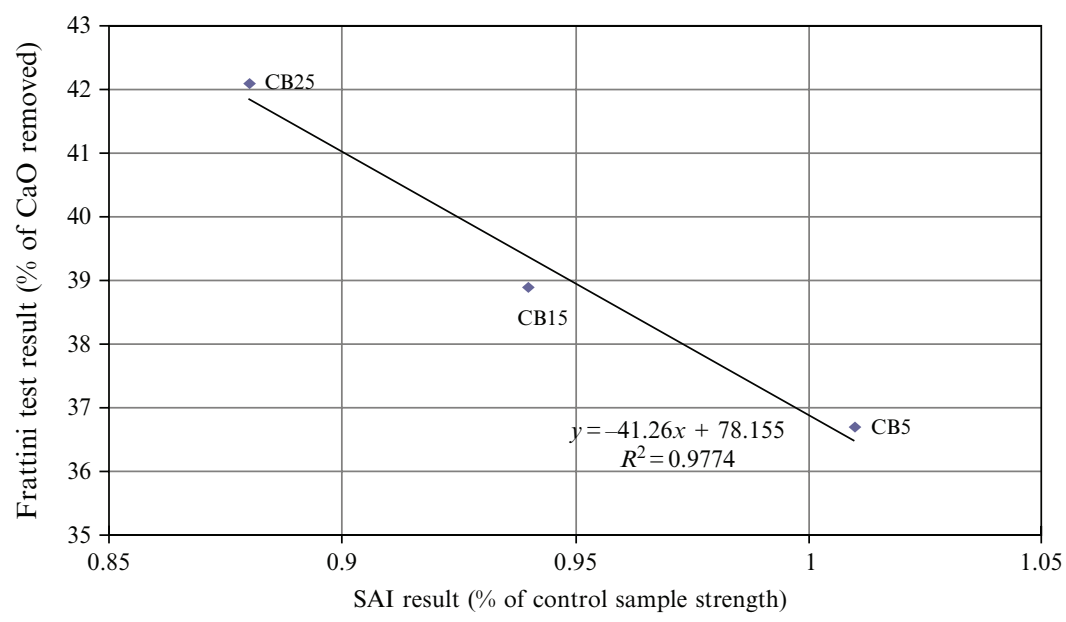

Fig. 17.7 Correlation between Frattini test and SAI results of CB.

\subsubsection{Discussion}

Figs. 17.5-17.7 show the possible trend qualitatively. The pozzolanic activity of FA powder is higher than that of HC powder, and the pozzolanic activity of HC powder is higher than that of CB powder. The negative correlation between SAI and Frattini test could be attributed to a large part of the $\mathrm{CB}$ powder that may unreact due to a high degree of crystallinity and plays a role as fine filler.

Some literature works mentioned that the Frattini test and the SAI could be the most accurate and reliable methods to assess pozzolanic activity (Donatello et al., 2010; Tironi et al., 2013; Malquori, 2013), and the most important quality for pozzolanic activity can be seen in the compressive strength (SAPRC (Standardisation Administration of the People's Republic of China), 2005; SBQTS (State Bureau of Quality and Technical Supervision), 1999; British Standard (BS) 3892, 1997; American Society for Testing and Materials (ASTM) C618, 2005). However, based on the investigations in Sections 17.2.6.1-17.2.6.3, both Frattini test and the SAI method may not be the only sufficient condition to judge the pozzolanic activity accurately and reliably due mainly to the following reasons:

- Both the pozzolanic activity and the fine filler effect may affect the SAI values of blended cement, but the effect of these two factors cannot be separated strictly.

- Generally speaking, the Frattini test and SAI method should be the necessary conditions to assess the pozzolanic activity. For instance, Fig. 17.4 indicates that the CB waste powder shows some pozzolanic activity, and SAI values of all the CB samples in Table 17.6 are greater than 0.75 or 0.8 (American Society for Testing and Materials (ASTM) C618, 2005), even though $\mathrm{CB}$ powder indicates a high degree of crystalline phases (quartz, silicon sulfide, etc.) in Fig. 17.3C. Actually, the pozzolanic active material should show the amorphous structure or low crystalline degree, similar to Fig. 17.3A for PO, Fig. 17.3B for FA and Fig. 17.3D for HC.

- Compared to the SAI and Frattini results, the combination of XRD analysis, the SAI test, and Frattini test could be more suitable to form a sufficient condition for an accurate and reliable assessment of the pozzolanic activity. 
In addition, it is worth noting the following differences between the $\mathrm{HC}$ and $\mathrm{CB}$ ceramic waste powders:

- Low degree crystalline quartz is the main compound of $\mathrm{HC}$ powder, and the $\mathrm{HC}$ waste shows some amorphous structure. CB powder shows relatively high degree of crystallinity.

- Except CB25, all the SAI values of HC and CB samples are higher than 0.8 at 7 days. At 28 days, the SAI values of $\mathrm{CB}$ declined with the increasing of waste content.

According to the Frattini results and SAI test, both the $\mathrm{HC}$ and $\mathrm{CB}$ ceramic waste powder show pozzolanic activity. However, on the basis of a comprehensive analysis of the high $\mathrm{pH}$-value and low crystalline degree, and other aspects like the grain size analysis as well as XRF analysis of the above investigations, $\mathrm{HC}$ powder could be more suitable for use in cement or concrete matrix than that of $\mathrm{CB}$ powder.

\subsection{Conclusions}

Samples with Portland cement, FA blended cement, the HC waste and CB waste powder with cement substitution ratios of $5 \%, 15 \%$, and $25 \%$ were experimentally investigated. The pozzolanic activity is an important precondition for reusing of the ceramic waste. The present study of ceramic waste powder led to the following conclusions:

The main chemical components of $\mathrm{HC}$ and $\mathrm{CB}$ waste powder are similar to those of FA and consist mainly of $\mathrm{SiO}_{2}$ and $\mathrm{Al}_{2} \mathrm{O}_{3}$.

Based on the Frattini results and SAI test, both the $\mathrm{HC}$ and $\mathrm{CB}$ ceramic waste powder show pozzolanic activity. However, the pozzolanic activity of $\mathrm{HC}$ powder was higher than that of CB waste powder.

The SAI values and Frattini results of $\mathrm{HC} 15$ are higher than those of $\mathrm{HC} 5$ and $\mathrm{HC} 25$. This may imply that $15 \%$ of $\mathrm{HC}$ could be a possible upper bound for an effective substitution ratio of cement.

For a waste powder with good pozzolanic activity like HC or FA, there should be a positive linear correlation between the Frattini and SAI results with a significant correlation coefficient.

The negative correlation between SAI and Frattini results of CB could be attributed to a large part of fine-milled CB waste powder that may unreact and plays a role as fine filler in the blended cement matrix.

The combination of XRD, SAI, and Frattini test could be a sufficient condition for an accurate and reliable assessment of the pozzolanic activity of the ceramic waste powder.

The possible substitution of cement by ceramic waste powder without further heating treatment will show major ecological benefits in terms of saving cement and reducing $\mathrm{CO}_{2}$ emission.

\section{Notation}

PO cement mortars/samples without ceramic waste additives.

HC/CB X cement mortars/samples with the ceramic waste replacement of X\%; for instance, HC/CB 10: samples with ceramic waste powder replacement of $10 \%$. 
FA Y cement mortars/samples with FA replacement of Y\%; for instance, FA5: samples with FA replacement of $5 \%$.

\section{Acknowledgments}

The authors acknowledge the National Natural Science Foundation of China: Grant 51578109, and Fundação para a Ciência e a Tecnologia (SFRH/BPD/22680/2005).

\section{References}

American Society for Testing and Materials (ASTM) C618, 2005. Standard Specification for Coal Fly Ash and Raw or Calcined Natural Pozzolan for Use in Concrete.

British Standard (BS) 3892, 1997. Pulverised-Fuel Ash. Part 1. Specification for Pulverised Fuel Ash for Use With Portland Cement.

British Standard Euronorm (BS EN) 196, 2011. Methods of Testing Cement. Part 5. Pozzolanicity Test for Pozzolanic Cement.

De Brito, J., Pereira, A.S., Correia, J.R., 2004. Mechanical behaviour of non-structural concrete made with recycled ceramic aggregates. Cem. Concr. Compos. 27 (4), 429-433.

Ding, Y., Jalali, S., Niederegger, C., 2010. Recycling of metamorphic rock waste in ecological cement. Proc. ICE Constr. Mater. 163, 143-148.

Donatello, S., Tyrer, M., Cheeseman, C.R., 2010. Comparison of test methods to assess pozzolanic activity. Cem. Concr. Compos. 32 (2), 121-127.

GB/T 2419-2005, 2005. China National Guideline "Test Method for Fluidity of Cement Mortar".

He, C., Osbaeck, B., Makovicky, E., 1995. Pozzolanic reactions of six principal clay minerals: activation, reactivity assessments and technological effects. Cem. Concr. Res. 25 (8), $1691-1702$.

ISO 679, 2009. Cement-Test Methods-Determination of Strength.

Kitsopoulos, K.P., Dunham, A.C., 1996. Heulandite and mordenite-rich tuffs from Greece: a potential source for pozzolanic materials. Miner. Depos. 31 (6), 576-583.

Lavat, A.E., Trezza, M.A., Poggi, M., 2009. Characterization of ceramic roof tile wastes as pozzolanic admixture. Waste Manag. 29 (5), 1666-1674.

Malquori, G., 2013. Portland-pozzolan cement. In: Proceedings of 4th International Symposium on the Chemistry of Cement, Washington, Vol. II. pp. 983-1000.

Matias, G., Faria, P., Torres, I., 2014a. Lime mortars with heat treated clays and ceramic waste: a review. Constr. Build. Mater. 7, 125-136.

Matias, G., Faria, P., Torres, I., 2014b. Lime mortars with ceramic wastes: characterization of components and their influence on the mechanical behaviour. Constr. Build. Mater. 73, $523-534$.

Mertens, G., Snellings, R., Van Balenb, K., Bicer-Simsirc, B., Verlooyd, P., Elsen, J., 2009. Pozzolanic reactions of common natural zeolites with lime and parameters affecting their reactivity. Cem. Concr. Res. 39, 233-240.

Pedersen, M.B., 2004. Alkali-Reactive and Inert Fillers in Concrete. Rheology of Fresh Mixtures and Expansive Reactions. Dissertation, Department of Structural Eng, Norwegian University of Science and Technology.

Pontes, J., Silva, A., Faria, P., 2013. Evaluation of pozzolanic reactivity of artificial pozzolans. Mater. Sci. Forum 730-732, 433-438. Trans Tech Publications, Switzerland. 
SAPRC (Standardisation Administration of the People's Republic of China), 2005. GB/T 28472005: Chinese Standard: Pozzolanic Materials Used for Cement Production. Standards Press of China, Beijing.

SBQTS (State Bureau of Quality and Technical Supervision), 1999. GB/T 17671-1999: Chinese Standard: Method of Testing Cements-Determination of Strength. Standards Press of China, Beijing.

Selman, M.M., Ali, A.M., 2012. The effect of alkalis on the properties of portland cement. Anbar J. Eng. Sci. 19979428, 25-38.

Shi, C., 2001. An overview on the activation of reactivity of natural pozzolans. Can. J. Civ. Eng. 28 (5), 778-786.

Silvestre, R., Medela, E., Garcíaa, A., Navasb, J., 2013. Utilizing recycled ceramic aggregates obtained from tile industry in the design of open graded wearing course on both laboratory and in situ basis. Mater. Des. 50, 471-478.

Smaoui, N., et al., 2005. Effects of alkali addition on the mechanical properties and durability of concrete. Cem. Concr. Res. 35, 203-212.

Tironi, A., Trezzaa, M., Scianb, A., Irassara, E., 2013. Assessment of pozzolanic activity of different calcined clays. Cem. Concr. Compos. 37, 319-327.

Wild, S., Gailius, A., Hansen, H., Pederson, L., Szwabowski, J., 1997. Pozzolanic properties of a variety of European clay bricks. Build. Res. Inf. 25 (3), 170-175. 